\title{
Genetic Diversity of Verticillium dahliae Isolates From Mint Detected with Genotyping by Sequencing
}

\author{
Jeremiah K. S. Dung, ${ }^{1, \dagger}$ Brian J. Knaus, ${ }^{2}$ Henry L. S. Fellows, ${ }^{3}$ Niklaus J. Grünwald, ${ }^{4}$ and Kelly J. Vining ${ }^{3}$ \\ ${ }^{1}$ Central Oregon Agricultural Research and Extension Center, Madras, OR 97741 \\ 2 Department of Botany and Plant Pathology, Oregon State University, Corvallis, OR 97331 \\ ${ }^{3}$ Department of Horticulture, Oregon State University, Corvallis, OR 97331 \\ ${ }^{4}$ Horticultural Crops Research Laboratory, U.S. Department of Agriculture Agricultural Research Service, Corvallis, OR 97331 \\ Accepted for publication 25 June 2019.
}

\begin{abstract}
Verticillium wilt is the most important disease threatening the commercial production of mint grown for essential oil. An important long-term goal for mint breeders is the production of cultivars with resistance to Verticillium wilt. Before that can be accomplished, a better understanding of the genetic variation within and among populations of Verticillium dahliae is needed. We characterized the extent of phenotypic and genetic diversity present in contemporary and archival populations of $V$. dahliae from mint fields in Oregon and other production regions of the United States using genotyping by sequencing, PCR assays for mating type and pathogenic race, vegetative compatibility group (VCG) tests, and

aggressiveness assays. We report that the population in the Pacific Northwest can be described as one common genetic group and four relatively rare genetic groups. Eighty-three percent of the isolates belonged to VCG2B, and all isolates possessed the MAT1-2 idiomorph and were characterized as pathogenic race 2 . These results indicate low levels of genetic diversity and a negligible risk of sexual recombination in populations of this host-adapted pathogen population. Knowledge of the genetic structure of $V$. dahliae in the Pacific Northwest will inform breeders about the diversity of pathogenicity factors that may need to be considered in their breeding programs.
\end{abstract}

Verticillium wilt, caused by the fungus Verticillium dahliae Kleb., is the most threatening disease of commercial peppermint (Mentha $\times$ piperita L.) and Scotch spearmint (M. $\times$ gracilis L.) production in the United States. Mint crops for distilled oil are primarily grown in the Pacific Northwest states of Washington and Oregon and, to a lesser extent, in the Midwest states of Wisconsin and Indiana. Although both spearmint and peppermint are produced, Verticillium wilt mainly affects the more commercially valuable peppermint, and the most prevalent peppermint cultivar, Black Mitcham peppermint, is particularly susceptible. Mint fields are typically maintained for up to 6 years, with one or two harvests per year, making soilborne diseases an especially challenging problem. V. dahliae is primarily spread by soil movement or the planting of infected rhizomes, and disease incidence in mint fields increases over time in perennial stands (Johnson et al. 2006). This causes decreased oil yields, increased weed pressure, and often early removal of stands. V. dahliae may persist in soil for more than a decade in the form of melanized resting structures called microsclerotia (Pegg and Brady 2002). For this reason, Verticilliuminfested fields tend to be taken out of mint production entirely.

$V$. dahliae isolates have been categorized based on both phenotypic and genotypic criteria. Vegetative compatibility groups (VCGs) are defined by the capacity of hyphae from nitrate nonutilizing mutants to anastomose with hyphae of known tester strains (Joaquim and Crowe 1990). Mint isolates are typically VCG2B and cause severe symptoms on mint but not on other hosts (Cirulli et al. 2010; Douhan and Johnson 2001). Isolates belonging to VCG2B have also been collected from diseased potato, cotton, artichoke, strawberry, and chickpea (Cirulli et al. 2010), but the

†Corresponding author: J. K. S. Dung; Jeremiah.Dung@oregonstate.edu

Funding: Funding for this research was provided by the Oregon Mint Commission.

The author(s) declare no conflict of interest.

(C) 2019 The American Phytopathological Society affiliation of isolates with a VCG does not necessarily mean that they are genetically homogenous, closely related phylogenetically, or pathogenic on other hosts associated with the same $V$. dahliae VCG (Jiménez-Gasco et al. 2014). Molecular evidence suggests a polyphyletic origin of VCG2B and subgroups of VCG2B are currently recognized (Jiménez-Díaz et al. 2011).

Some $V$. dahliae isolates, including those from mint, are highly host adapted (Bhat and Subbarao 1999; Daayf et al. 1995; Johnson and Dung 2010), and a mint-adapted pathotype of $V$. dahliae was previously proposed (de Jonge et al. 2012; Douhan and Johnson 2001; Dung et al. 2010; Short et al. 2014b). Some host-adapted genotypes of $V$. dahliae are attributable, at least in part, to gene-forgene interactions between $V$. dahliae and the host. At least two pathogenic races of $V$. dahliae have been defined among populations infecting tomato, lettuce, and sunflower (Alexander 1962; Botero and Vazquez 1982; Vallad et al. 2006), with resistance to race 1 strains being conferred by a single gene (Fick and Zimmer 1974; Fradin et al. 2009; Hayes et al. 2007; Schaible et al. 1951). Sources of resistance to race 2 strains are not currently available in most crops, and differential responses to race 2 isolates in some tomato cultivars suggest that race 2 may be heterogeneous (de Jonge et al. 2012; Usami et al. 2017). A previous study tested 16 V. dahliae isolates collected from mint in Washington State and all 16 isolates were determined to be race 2 (Short et al. 2014b); however, it is not known which race(s) of $V$. dahliae cause Verticillium wilt in commercial mint production fields of Oregon.

$V$. dahliae is an ascomycete fungus for which no sexual stage has been reported, and it has a highly clonal population structure (Fradin and Thomma 2006; Gurung et al. 2014; Milgroom et al. 2014). However, mating type idiomorphs have been described in the fungus (Usami et al. 2008). Mating types are defined based on genotypes at the MAT locus, which is known to regulate sexual reproduction between strains of heterothallic ascomycetes (Turgeon 1998; Turgeon and Yoder 2000). To date, most V. dahliae isolates have been observed to possess the MAT1-2 idiomorph (Dung et al. 2013; Milgroom et al. 2014; Short et al. 2014a; Usami et al. 2008, 2009). It has been hypothesized that sexual reproduction 
was lost from $V$. dahliae recently, and that current clonal lineages differentiated and arose via previous ancestral recombination events (Atallah et al. 2010, 2011; Milgroom et al. 2014).

The development of Verticillium wilt-resistant mint cultivars is a long-term priority of the U.S. mint industry. A better understanding of the genetic diversity and potential for sexual reproduction of $V$. dahliae populations affecting Oregon mint production will help inform breeding programs and improve sustainable management practices for Verticillium wilt in mint. Genetic differences have been observed among and within populations of $V$. dahliae from different plant hosts, including mint, potato, cotton, olive, and artichoke (Dung et al. 2013; Jiménez-Díaz et al. 2006; Milgroom et al. 2016). In order to determine the feasibility of achieving durable wilt resistance, it is important to understand the current phenotypic and genetic diversity of the pathogen population in commercial mint production systems. In this study, we used genotyping by sequencing (GBS), PCR assays for mating type and pathogenic race, VCG tests, and aggressiveness assays of $V$. dahliae isolates collected from infected mint in Oregon to characterize the extent of phenotypic and genetic diversity present in this highly host-adapted population.

\section{MATERIALS AND METHODS}

Fungal isolates and DNA extraction. Two sets of $V$. dahliae isolates were included in this study: (i) a contemporary collection of 59 isolates collected in 2015 from 28 symptomatic peppermint fields in the Willamette Valley of Oregon and in central Oregon; and (ii) an archival collection of 41 isolates collected from symptomatic peppermint, native spearmint (M. spicata L.), and Scotch spearmint fields in Oregon, Washington, Idaho, and Montana between 1996 and 2014. Surface-sterilized mint stems were plated onto selective NP-10 medium (Butterfield and DeVay 1977; Kabir et al. 2004) to recover $V$. dahliae. Isolates were subcultured on $1 \%$ water agar and hyphal-tipped prior to storage on sterile filter paper at $-20^{\circ} \mathrm{C}$ and subsequent use.

Isolates were grown on potato dextrose agar for 5 to 10 days at $23^{\circ} \mathrm{C}$ in the dark. Plugs of mycelia from actively growing plates were transferred to beakers containing Czapek-Dox broth and incubated for approximately 1 week at $23^{\circ} \mathrm{C}$ in the dark. Mycelia were then retrieved, rinsed with sterile deionized water, and lyophilized for 24 to $48 \mathrm{~h}$. Lyophilized tissue was stored at $-80^{\circ} \mathrm{C}$ until use.

DNA from approximately $20 \mathrm{mg}$ of lyophilized tissue from each sample was obtained using the glass bead breakage method with phenol and chloroform extraction (Dobinson et al. 2000). The quality and concentration of genomic DNA was determined using gel electrophoresis and a NanoDrop 2000c spectrophotometer (Thermo Fisher Scientific, Waltham, MA). The DNA was diluted to $2 \mathrm{ng} / \mu \mathrm{l}$ and stored at $-20^{\circ} \mathrm{C}$ until needed.

Genotyping by sequencing. GBS was conducted at the Oregon State University Center for Genome Research and Biocomputing. DNA was extracted from frozen tissue on a KingFisher Flex system (Thermo Fisher Scientific, Waltham, MA). A minimum of $100 \mathrm{ng}$ of DNA per sample was digested with ApeKI restriction enzyme (5 U), followed by sequencing adapter ligation (Elshire et al. 2011). GBS libraries were sequenced in a single lane on an Illumina HiSeq3000 system $(1 \times 151 \mathrm{bp})$.

Data processing, single nucleotide polymorphism calling, and discriminant analysis of principal components. FASTQ format reads (Cock et al. 2010) were mapped to the VdLs.17 reference (Faino et al. 2015) using bwa 0.7.5a-r405 (Li and Durbin 2009) and single nucleotide polymorphisms (SNPs) were called using TASSEL 3.0 with default parameters (Bradbury et al. 2007). These bioinformatic steps were provided as a service by the Oregon State University Center for Genome Research and Biocomputing.

Variants in the variant call format (Danecek et al. 2011) were further processed using vcfR (Knaus and Grünwald 2017). Violin plots were used to visualize the distribution of sequence depth (DP) for variants from each sample. Similar to other GBS libraries, many samples were observed to have a bimodal distribution of depth with one peak slightly above $100 \times$. Therefore, an upper threshold of $100 \times$ was used to omit these unusually high coverage variants and to attain samples with a unimodal distribution. For each sample, the fifth and 95th percentiles of DP were used to identify variants of unusual DP. These variants were rescored as missing data. Variants with less than $2 \times$ coverage were also marked as missing data. Variants with $>5 \%$ missing data over the 96 samples were then removed from the data set. Samples that contained $>20 \%$ missing data were then omitted from the data set. This resulted in a production data set that was used for all downstream analyses. Variants were then categorized by genome feature annotation using R software (R Core Team 2017).

V. dahliae is in the Ascomycota and is expected to be haploid. The TASSEL pipeline resulted in diploid variant calls. We used histograms of allele balance (Knaus and Grünwald 2018) to validate whether isolates were actually haploid. Variants that were called as homozygotes were rescored as missing data. The allele depth $(\mathrm{AD})$ for each variant was then used to create histograms from the proportion of times each allele was sequenced. The data were phased using Beagle (Browning and Browning 2007). Information from the $\mathrm{AD}$ histograms was then used to divide the data into samples that were haploid and samples that were diploid. For the diploid samples, we split the phased genotypes into two haplotypes. For the haploids, we set all heterozygotes as missing genotypes and rescored homozygotes as haploid.

Discriminant analysis of principal components (DAPC) (Jombart et al. 2010) was implemented with the R package adegenet (Jombart 2008) to assign samples to groups. Most of the variation in the data set could be explained by the first four principal components. However, to be as inclusive as possible, we performed downstream analysis steps on the first 40 principal components. The function find.clusters() was used with 40 principal component axes and five clusters. The function dapc() was then used with 40 principal components and three discriminant axes. The results from the DAPC were visualized in R ( $\mathrm{R}$ Core Team 2017) using ggplot2 (Wickham 2016). The relationships among groups determined by $k$-means clustering were visualized with principal components analysis using the R package adegenet (Jombart 2008).

To infer reproductive mode, we calculated linkage disequilibrium. We used the vcftools module "-hap-r2" to calculate $D$ ' (Danecek et al. 2011). The $D^{\prime}$ values were squared and then plotted in $\mathrm{R}$.

Mating type and pathogenic race determination. The V. dahliae isolates were characterized according to mating type using a previously published multiplex PCR assay (Usami et al. 2009). Primer pairs VdMAT1-1a/VdMAT1-1b and VdMAT1-2a/VdMAT12b were expected to amplify the MAT1-1 ( $\approx 600$-bp product) and MAT1-2 ( $\approx 400$-bp product) idiomorphs, respectively. PCR reactions were carried out as previously described by Dung et al. (2013). Isolates 461 (from tomato) and 20 (from native spearmint) were included as positive controls for mating types MAT1-1 and MAT1-2, respectively. A negative control consisting of water was included for all reactions. All reactions were repeated once.

The pathogenic race of $V$. dahliae isolates was determined using two previously developed race-specific primer pairs, VdAve1F/ VdAve1R (race 1) and $\mathrm{VdR} 2 \mathrm{~F} / \mathrm{VdR} 2 \mathrm{R}$ (race 2), as previously described (Short et al. 2014b; Usami et al. 2008). Race 1 isolates were expected to have bands at 256 and $900 \mathrm{bp}$ and race 2 isolates were expected to have a band at 256 bp (Short et al. 2014b). Isolates Ls16 and Ls17, both from lettuce, served as positive controls for races 1 and 2, respectively. Water served as a negative control for the PCR runs. Both PCR reactions (race 1 and race 2) were repeated for 24 isolates to confirm reproducibility and validate the results.

The PCR products were electrophoresed on 1.25 to $1.5 \%$ (wt/vol) agarose gels containing $1 \times$ TAE buffer at $90 \mathrm{~V}$ for 75 to $90 \mathrm{~min}$. 
Bands were visualized using GelRed fluorescent DNA stain (Biotium Inc., Fremont, CA). The gels were visualized alongside a 100-bp ladder and documented with a Gel-Doc It2 Imager.

For MAT1-2 and VdRasGTPase, PCR primers flanking SNPs detected by GBS were used to amplify and clone products of 313 and $301 \mathrm{bp}$, respectively. PCR products were cloned into TOPO-TA cloning vectors (Invitrogen) and used to transform DH-5 $\alpha$ cells. Twelve clones of each target were submitted for Sanger sequencing at the Oregon State University Center for Genome Research and Biocomputing.

VCG determination. Nitrate nonutilizing mutants of $54 \mathrm{mint}$ isolates collected from Oregon in 2015 were generated and VCG testing was performed as described by Joaquim and Crowe (1990) with a few modifications (Weiland et al. 2018). Nitrate nonutilizing mutants were paired with Nit1 and NitM mutants of standardized testing strains for VCG1 (V-44), VCG2A (PH), VCG2B (115), VCG3 (70-21), VCG4A (BB), and VCG4B (S39). Plates were checked for vegetative compatibility for 2 to 4 weeks and rated as previously described (Weiland et al. 2018). The VCGs of isolates in the archival collection were previously determined by Douhan and Johnson (2001) and Dung et al. (2013).

Aggressiveness assays. A subset of three $V$. dahliae isolates representing the three distinct GBS groups observed in Oregon were tested for aggressiveness on Black Mitcham peppermint, which is susceptible to Verticillium wilt, and native spearmint, which is resistant to Verticillium wilt. Isolates 15-059 and 97-098-1 were also included. Rooted mint plugs were obtained from the JacksonBrush Plant Laboratory (Norris, MT) and planted into 4-inch square pots filled with Sunshine Mix \#4 (Sun Gro Horticulture, Agawam, MA). Plants were grown in a greenhouse for 2 weeks prior to inoculation.

V. dahliae isolates M-53 (GBS group 2), Vd-1127 (GBS group 3), 15-034-F (GBS group 4), 15-059-F (potential diploid), and 97-0981 (potential diploid) were grown in Czapek-Dox broth and conidial suspensions were prepared at a concentration of $10^{6}$ conidia $/ \mathrm{ml}$. Plants were inoculated by drenching the potting mix to a final inoculum concentration of $10^{5}$ conidia/ $\mathrm{cm}^{3}$ potting mix. A noninoculated control was also included. All treatments were replicated four times and arranged in a randomized complete block design in a greenhouse. Symptoms were recorded weekly (every 6 to 9 days) at three time points starting at 3 to 4 weeks postinoculation using the following disease severity index (DSI): 0 , no visible symptoms; 1 , mild apical chlorosis and/or wilt; 2, asymmetrical apical growth and/or anthocyanescence; 3, distinct basal chlorosis and/or wilt; 4 , necrosis in $\geq 50 \%$ of the plant; and 5, dead or nearly dead plant. Disease severity ratings over time were converted to area under disease progress curves (AUDPCs) as previously described (Dung et al. 2010). Aboveground leaves and stems were harvested at flowering and dried for 2 weeks in the greenhouse, and dry hay yields were recorded. Yields were converted to yield ratios as previously described (Dung et al. 2010). Yield ratios $<1$ indicated reduced yields compared with the mean yield of the noninoculated control treatment within the same mint species. Plants were allowed to regrow for 4 to 6 weeks, after which a DSI rating was recorded and regrowth was harvested to calculate regrowth yield ratios. The experiment was repeated once.

Normality and heteroscedasticity of data were assessed using the Shapiro-Wilk and Kolmogorov-Smirnov tests at $\alpha=0.05$ and by examining plotted studentized residuals using PROC UNIVARIATE and PROC PLOT in SAS 9.4 software (SAS Institute, Cary, NC). Analysis of variance (ANOVA) was conducted on AUDPC, yield ratio, and regrowth yield ratio data using PROC MIXED in SAS. Data were analyzed as a two-way factorial design, with mint species and isolate as main effects and trials and blocks as random effects. Multiple pairwise comparisons were performed using Tukey's honest significant difference test at $P<0.05$.

Nonparametric DSI ranking data were aligned and ranked using ARTool (Wobbrock et al. 2011) followed by a factorial ANOVA on aligned and ranked data using PROC MIXED in SAS. DSI ranking data were then analyzed separately for each mint variety using the NPAR1WAY procedure and Kruskal-Wallis test in SAS (Wobbrock et al. 2011).

\section{RESULTS}

Genotyping by sequencing. GBS of 96 samples yielded 55.4 Gbp of sequence data, and resulted in a data set consisting of 112,384 raw variants. Allele balance histograms determined that two samples (15-059-f and 97-098-1) appeared diploid. Quality control steps resulted in a production data set that contained 88 haplotypes ( 84 haploid samples and two diploid samples resolved into haplotypes) samples and 5,631 variants.

SNPs were identified relative to the $35-\mathrm{Mbp}$ reference genome (Faino et al. 2015). Protein-coding genes in the reference are annotated with "gene" and "mRNA" categories, which have matching start and end coordinates. Within these genic regions are "coding sequence" (CDS) and "exon" annotations, which are overlapping but may have slightly different coordinates based on the presence of alternative start codons and potential alternative splicing. A total of 5,631 SNP variants were observed relative to the reference. Of these, 2,857 variants were observed from regions annotated as gene/mRNA. Within genic annotations, 2,544 variants were observed in exons, and 2,485 variants were located CDSs.

DAPC resulted in the sample being sorted into five groups (Figs. 1 and 2). Because the genlight object cannot accommodate loci with more than two alleles, 142 loci $(2.52 \%)$ were omitted. The first four eigenvalues accounted for $95.5 \%$ of the variation in the data set. $k$ means clustering was used to assign individuals to groups. Above a group number of five, no appreciable improvement in the Bayesian Information Criterion was observed; therefore, a maximum number of five groups was selected. DAPC was performed on 40 principal components using five groups and three discriminant axes. Most of the isolates collected from Oregon were assigned to one group (Fig. 1). However, Oregon samples were represented in three of the five groups. Washington State was included in all five groups, including a group with a single member. Montana samples were included in three groups that also included samples from Oregon and Washington State. Samples from Montana were predominantly assigned to group 3, whereas isolates from Oregon and Washington State were primarily assigned to group 4. California, Idaho, Indiana, and Michigan each were represented by a single sample, and none belonged to groups that were not observed in Washington State. Principal components analysis indicated that these genetic groups were well differentiated relative to the amount of diversity observed within any of these groups.

Analysis of linkage demonstrated that the sampled genomes were highly linked (Fig. 3). Most pairwise comparisons of linkage were completely linked (Fig. 3A) and this linkage did not appear to decay with physical distance (Fig. 3B).

Mating type and pathogenic race determination. Genes implicated in mating type and pathogenicity (Klimes et al. 2015) were further examined to determine whether SNPs were present in these genes among the fungal samples. SNPs detected by GBS were confirmed by PCR product cloning followed by Sanger sequencing. All V. dahliae isolates amplified a 400-bp band in the MAT-specific PCR assay and were designated as mating type MAT1-2 (Tables 1 and 2). For the pathogenic race assay, all $V$. dahliae isolates produced a $\sim 256$-bp band with the VdR2 primers and failed to produce bands at $\sim 900$ and $\sim 256$-bp with the VdAve1 primers, indicating that all isolates belonged to race 2 (Fig. 4; Tables 1 and 2). Only two genes contained nonsynonymous substitutions in their coding regions (Table 3 ). In the MAT 1-2 idiomorph, the minor allele was observed in $20.45 \%$ of the alleles and was distributed in samples from Oregon, Washington, Montana, and Idaho. In VdRasGTPase, the minor allele was observed at a frequency of $2.27 \%$ and was only observed in Oregon. The VdRasGTPase minor 
alleles were only observed in the isolates we determined to be diploid.

VCG determination. Fifty of the mint isolates collected from Oregon in 2015 were classified as VCG2B based on complementation with tester strains, consistent with the mint pathotype of $V$. dahliae. One isolate paired with VCG4A, and two isolates paired with both VCG2B and VCG4A. Another isolate paired with both VCG4A and VCG4B, placing it in VCG4A/B. Results are detailed in Tables 1 and 3.

Aggressiveness assays. ANOVA did not detect a significant difference among trials for AUDPC $(P=0.1461)$, yield ratio
( $P=0.0861)$, regrowth DSI ratings $(P=1.0000)$, or regrowth yield ratio $(P=0.08674)$, so data from both experiments were analyzed together. A significant mint $\times$ isolate interaction was observed for AUDPC values $(P<0.0001)$ but not yield ratios $(P=0.0681)$; however, a significant effect of mint $(P=0.0002)$ and isolate $(P=$ $0.0221)$ was observed on yield ratios. Overall, native spearmint exhibited relatively minor symptoms compared with Black Mitcham peppermint (Table 4). Compared with noninoculated controls, yield ratios of Black Mitcham were significantly reduced by one isolate. A significant mint $x$ isolate interaction was also observed on regrowth DSI ratings and regrowth yield ratios
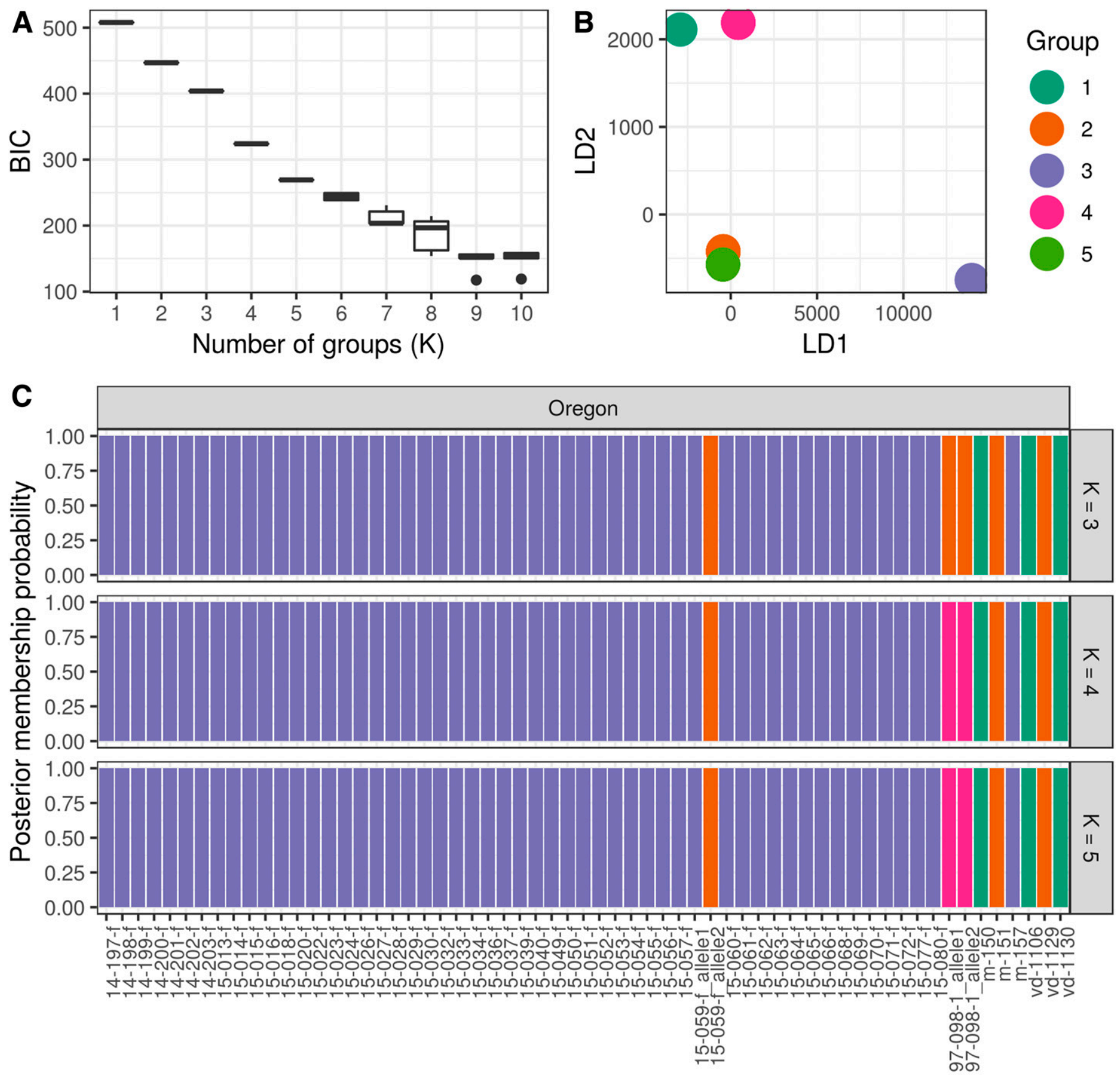

Isolate

Fig. 1. Grouping of isolates was stable regardless of the number of groups chosen for assignment. A, $k$-means clustering performance (BIC) decreased until around nine groups were selected. B, Scatterplot of discriminant functions. Note that groups 1 and 4 as well as 2 and 5 do not differentiate dramatically and that variation within each group is so low that each sample's point lines up on top of each other, creating the illusion that there is one point. C, Bar plots of posterior membership probabilities for the number of groups assigned as 3 to 5. This was an analysis of all of the samples but the presented bar plots are the subset from Oregon. The single isolate assigned to group 5 was from Washington (Fig. 3). BIC = Bayesian Information Criterion and LD = linkage disequilibrium. 
$(P<0.0001)$. All isolates caused severe symptoms (DSI ratings $>4)$ in Black Mitcham and four of five of the isolates significantly reduced regrowth yield ratios compared with noninoculated controls (Table 4). In contrast, only one isolate caused mild disease symptoms in native spearmint upon regrowth and yield ratios of native spearmint were not significantly reduced by any of the isolates.

\section{DISCUSSION}

In this study, GBS revealed genetic diversity in the form of genome-wide SNP profiles that clustered the V. dahliae isolates that were collected from mint into five distinct groups. A strong clonal structure was also observed, similar to the findings of Milgroom et al. (2014) and Rafiei et al. (2018), who sampled V. dahliae isolates from southern Spain and from Iran, respectively. However, unlike the aforementioned studies, the present study focused on hostadapted isolates from a single host genus, Mentha. A strong clonal structure was also observed among $V$. dahliae isolates from mint using microsatellite markers (Dung et al. 2013), reinforcing a previous study that demonstrated a correspondence between certain clonal lineages observed using SNPs and clonal haplotypes observed with microsatellites (Rafiei et al. 2018).

Collectively, the $V$. dahliae isolates in this study largely represented the Pacific Northwest mint-growing region of the United States. The largest number of samples was collected from Oregon, which were represented in groups 1 to 4 (Fig. 2). All of the contemporary Oregon samples collected in 2015 belonged to group 4 , with the exception of one sample that belonged to group 2. However, among the archival Oregon samples collected prior to 2015, a single isolate belonged to group 4. The widespread distribution of group 4 genotypes among contemporary Oregon mint fields suggests an epidemic population structure similar to what was proposed for defoliating strains of $V$. dahliae affecting cotton, okra, and olive (Milgroom et al. 2016). Such a population structure may be the result of the introduction of mint-adapted
V. dahliae genotypes into mint fields over the past 20 years through the planting of infected rhizomes or movement of infested soil, followed by host-selection pressure (Wheeler and Johnson 2019). This is a likely scenario given that commercial mint production relies on vegetative propagation of mint rhizomes, providing opportunities for pathogen dispersal from field to field and among mint-producing states. Mint rootstock certification programs that work to reduce the production and dissemination of diseased or infested planting materials can provide long-term benefit by reducing the infestation of new fields and the spread of mintadapted isolates in commercial production systems.

Far fewer $V$. dahliae samples were collected from California, Montana, and the Midwest than from Oregon and Washington State. Therefore, it is not possible to ascertain any relationships between genotype and geography. Regardless, even with limited sample sizes, group membership was distributed. Washington State isolates belonged to four groups, and Montana isolates belonged to three
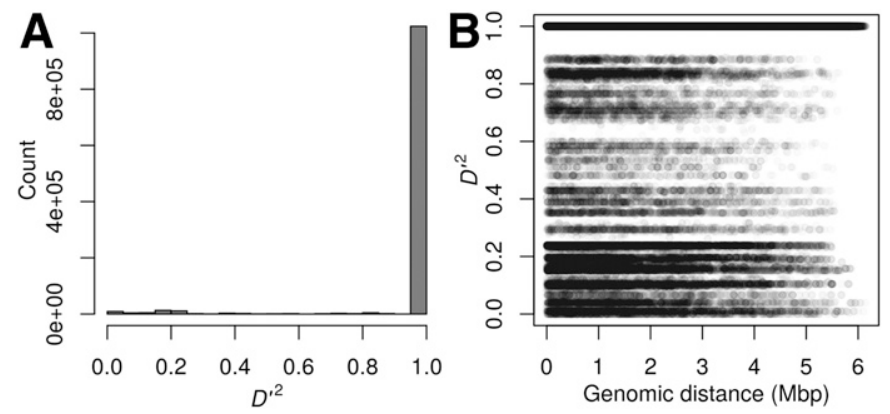

Fig. 3. Genomes of Verticillium dahliae were highly linked. A, The histogram of $D^{\prime 2}$ demonstrated that most pairwise comparisons among variants were highly linked. B, The scatterplot of $D^{\prime 2}$ as a function of physical distance demonstrates that this high level of linkage occurs over large regions of the genome.
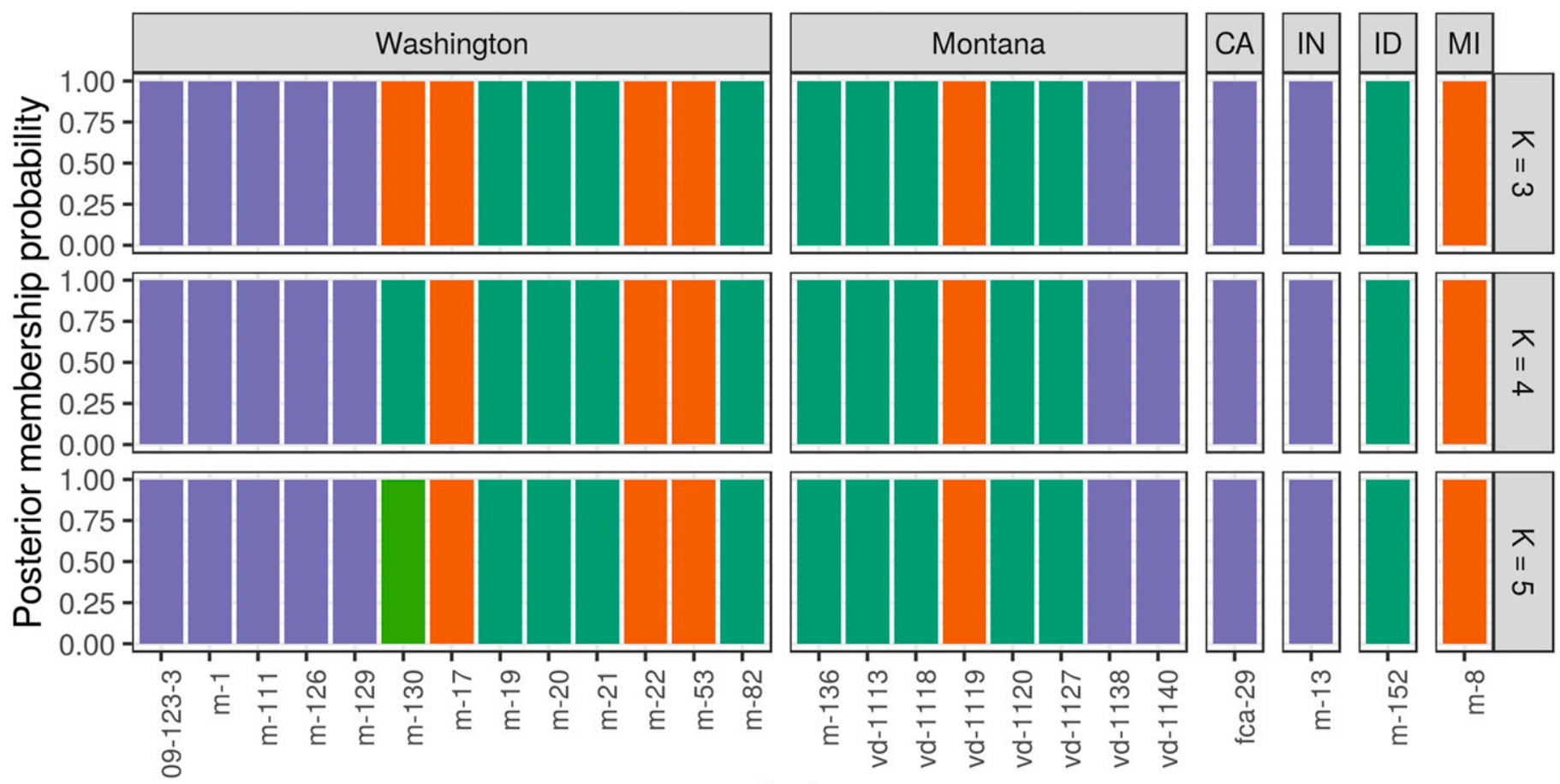

$\infty$

$\stackrel{1}{\varepsilon}$

\section{Isolate}

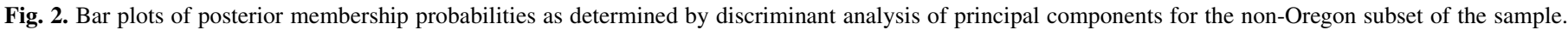

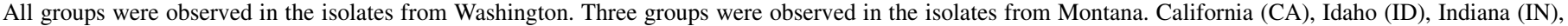
and Michigan (MI) each consisted of a single sample and no unique groups were observed. 


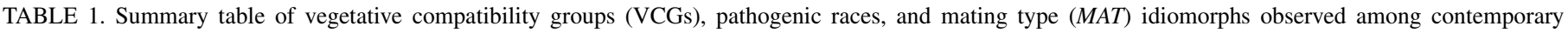
Verticillium dahliae isolates collected from Oregon peppermint fields in 2015

\begin{tabular}{|c|c|c|c|c|c|c|c|c|c|c|c|c|}
\hline \multirow[b]{2}{*}{ Production region } & \multirow[b]{2}{*}{ Isolates $(n)$} & \multicolumn{7}{|c|}{ VCG } & \multicolumn{2}{|c|}{ Pathogenic race } & \multicolumn{2}{|c|}{$M A T$ idiomorph } \\
\hline & & $2 \mathrm{~A}$ & $2 \mathrm{~A} / \mathrm{B}$ & $2 \mathrm{~B}$ & $2 \mathrm{~B} / 4 \mathrm{~A}$ & $4 \mathrm{~A}$ & $4 \mathrm{AB}$ & $\mathrm{ND}^{\mathrm{z}}$ & Race 1 & Race 2 & $M A T 1-1$ & $M A T 1-2$ \\
\hline Central Oregon & 19 & 0 & 0 & 15 & 2 & 0 & 0 & 2 & 0 & 19 & 0 & 19 \\
\hline Willamette Valley & 38 & 0 & 0 & 33 & 0 & 1 & 1 & 3 & 0 & 38 & 0 & 38 \\
\hline Grande Ronde Valley & 2 & 0 & 0 & 2 & 0 & 0 & 0 & 0 & 0 & 2 & 0 & 2 \\
\hline Total & 59 & 0 & 0 & 50 & 2 & 1 & 1 & 5 & 0 & 59 & 0 & 59 \\
\hline
\end{tabular}

${ }^{\mathrm{z}} \mathrm{ND}=$ not determined.

TABLE 2. Summary table of vegetative compatibility groups (VCGs), pathogenic races, and mating type (MAT) idiomorphs observed among archival Verticillium dahliae isolates collected from mint fields in various states between 1996 and 2014

\begin{tabular}{|c|c|c|c|c|c|c|c|c|c|c|c|c|c|}
\hline \multirow[b]{2}{*}{ Mint species } & \multirow[b]{2}{*}{ Production region } & \multirow[b]{2}{*}{ Isolates $(n)$} & \multicolumn{7}{|c|}{$\mathrm{VCG}^{\mathrm{z}}$} & \multicolumn{2}{|c|}{ Pathogenic race } & \multicolumn{2}{|c|}{$M A T$ idiomorph } \\
\hline & & & $2 \mathrm{~A}$ & $2 \mathrm{~A} / \mathrm{B}$ & $2 \mathrm{~B}$ & $2 \mathrm{~B} / 4 \mathrm{~A}$ & $4 \mathrm{~A}$ & $4 \mathrm{AB}$ & ND & Race 1 & Race 2 & MAT1-1 & MAT1-2 \\
\hline \multirow[t]{7}{*}{ Peppermint } & Idaho & 1 & 0 & 0 & 1 & 0 & 0 & 0 & 0 & 0 & 1 & 0 & 1 \\
\hline & Indiana & 1 & 0 & 0 & 1 & 0 & 0 & 0 & 0 & 0 & 1 & 0 & 1 \\
\hline & Michigan & 1 & 0 & 0 & 1 & 0 & 0 & 0 & 0 & 0 & 1 & 0 & 1 \\
\hline & Montana & 9 & 0 & 0 & 6 & 1 & 1 & 0 & 1 & 0 & 9 & 0 & 9 \\
\hline & Oregon & 14 & 1 & 1 & 10 & 2 & 0 & 0 & 0 & 0 & 14 & 0 & 14 \\
\hline & Washington & 4 & 0 & 0 & 4 & 0 & 0 & 0 & 0 & 0 & 4 & 0 & 4 \\
\hline & Unknown & 1 & 0 & 0 & 1 & 0 & 0 & 0 & 0 & 0 & 1 & 0 & 1 \\
\hline Native spearmint & Washington & 5 & 0 & 1 & 4 & 0 & 0 & 0 & 0 & 0 & 5 & 0 & 5 \\
\hline \multirow[t]{3}{*}{ Scotch spearmint } & Indiana & 1 & 0 & 0 & 1 & 0 & 0 & 0 & 0 & 0 & 1 & 0 & 1 \\
\hline & Washington & 4 & 0 & 0 & 4 & 0 & 0 & 0 & 0 & 0 & 4 & 0 & 4 \\
\hline & Total & 41 & 1 & 2 & 33 & 3 & 1 & 0 & 1 & 0 & 41 & 0 & 41 \\
\hline
\end{tabular}

${ }^{\mathrm{z}}$ The VCGs of the isolates were previously determined by Douhan and Johnson (2001) and Dung et al. (2013).

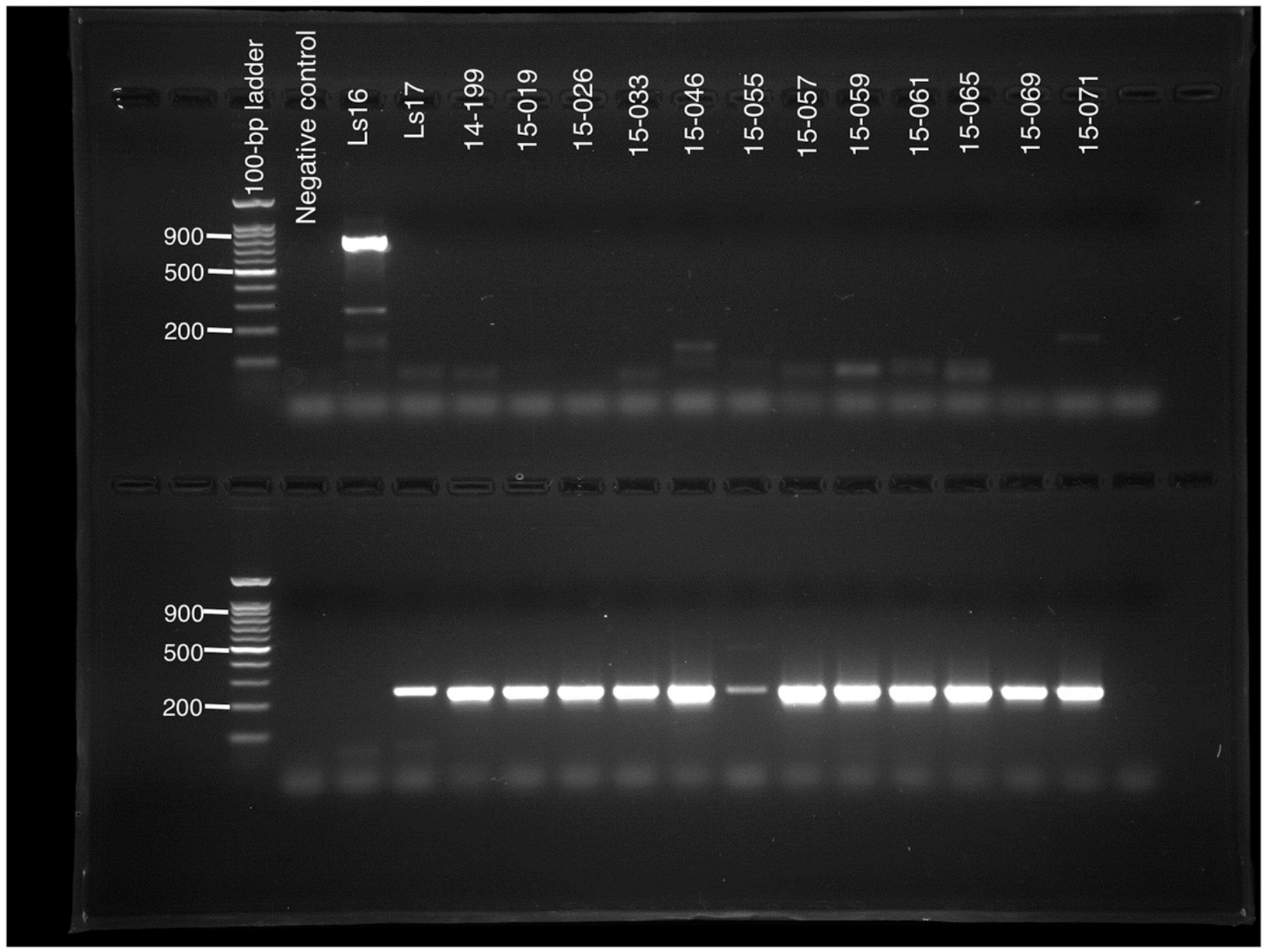

Fig. 4. Race 1 (top) and race 2 (bottom) PCR amplicons generated with Verticillium dahliae race-specific primers. Isolates Ls16 and Ls17 were collected from lettuce and used as race 1 and race 2 positive controls, respectively. The race 1 control is expected to generate a band approximately $900 \mathrm{bp}$ in size, and the race 2 control is expected to produce a band approximately 256 bp in size. The remaining isolates were collected from peppermint grown in Oregon between 2014 and 2015. 
groups. The pairs of isolates from California, Idaho, and Michigan belonged to groups 1,3, and 2, respectively; however, group 4 was the most prevalent overall and was represented by isolates collected from Oregon, Washington State, California, Montana, and Indiana. Such a widespread distribution of group 4 genotypes supports a proposed epidemic population structure of mint-adapted $V$. dahliae isolates. In the mid-1800s, mint production was concentrated in the Midwest (Indiana, Michigan, Wisconsin) and later migrated west. Based on our results, it is reasonable to hypothesize that the group 2, group 3, and group 4 genotypes originated in the Midwest and then were transported west via propagation and distribution networks. More extensive sampling in the Midwest would be necessary to test this hypothesis.

Nonsynonymous polymorphisms were observed at two loci with known or putative functions related to mating type determination (MAT1-2) and pathogenicity (VdRasGTPase). For MAT1-2, the minor allele was observed in isolates from different states; for VdRasGTPase, the minor allele was observed in Oregon samples only. Because of the limited sampling outside of the Pacific Northwest, additional sampling would be necessary to determine the breadth of the geographic distribution of these variants.

A majority of mint isolates $(83 \%)$ belonged to VCG2B. This is not surprising given the strong association previously established between mint and this VCG (Douhan and Johnson 2001; Dung et al. 2013). In certain instances, molecular markers have been used to distinguish VCGs and reveal genetic diversity among $V$. dahliae isolates within VCGs, including VCG2B isolates from mint (Dung et al. 2013; Jiménez-Gasco et al. 2014; Martín-Sanz et al. 2018; Rafiei et al. 2018). In this case, correlations were not observed between VCG and SNP profiles, but this study does confirm that extensive genetic polymorphisms can exist among isolates of a single VCG from a single host genus.

Based on the results of this and other studies, the MAT1-2 idiomorph appears to be the predominant mating type idiomorph among $V$. dahliae isolates from mint and other important host crops around the world (Dung et al. 2013; Milgroom et al. 2014; Rafiei et al. 2018; Short et al. 2014a; Usami et al. 2008). The MAT1-1 idiomorph has been reported in some isolates of $V$. dahliae, but in a relatively small number compared with the frequency of MAT1-2 idiomorphs that are encountered. The lack of both mating types in mint and other host crops in the Pacific Northwest (Dung et al. 2013) suggests that sexual reproduction is unlikely to occur among $V$. dahliae isolates in commercial mint production systems of the Pacific Northwest. However, the potential exists for heterokaryon formation, hybridization, and/or parasexual recombination in planta among isolates, and even among isolates belonging to different VCGs or different Verticillium species (Hastie 1964, 1973; Inderbitzin et al. 2011; McGuire et al. 2005; Wheeler and Johnson 2019).

Host resistance can be an effective, long-term component of an integrated management program for Verticillium wilt. Cultivars of tomato and lettuce that are resistant to race 1 isolates of $V$. dahliae have been successfully identified and deployed into commercial production systems (Atallah et al. 2011; Baergen et al. 1993; Hayes et al. 2011). The prevalence of $V$. dahliae race 2 strains observed in association with mint crops in the Pacific Northwest implies the importance of developing mint cultivars that are resistant to race 2 strains of $V$. dahliae. Unfortunately, sources of complete resistance to race 2 isolates of $V$. dahliae currently remain unidentified and pathogenic variation among race 2 isolates has been reported (Usami et al. 2017); more research is needed to fully understand the mechanism(s) of race 2 pathogenicity among $V$. dahliae isolates. All five race 2 isolates that were tested for pathogenicity in this study were aggressive on Black Mitcham peppermint, but more isolates need to be tested in order to determine the range of pathogenicity within each GBS group.

The population of $V$. dahliae affecting mint production in Oregon and Washington State appears to be a population of low diversity. Among the 100 isolates tested, only one mating type idiomorph (MAT1-2) and one pathogenic race (race 2) was observed. However, nonsynonymous substitution polymorphisms were detected at mating type-associated and pathogenicity-related genes, suggesting

TABLE 3. Two genes associated with mating type and pathogenicity contain nonsynonymous single nucleotide polymorphisms (SNPs)

\begin{tabular}{lccccccc}
\hline Gene name & \multicolumn{1}{c}{ Function } & Chromosome & Start position & Stop position & SNPs $(n)$ & Codon changes & Strand \\
\hline MAT1-2 & $\begin{array}{c}\text { Mating type-associated gene, } \\
\text { pathogenicity related }\end{array}$ & 3 & $1,655,533$ & $1,647,040$ & 1 & Thr $<->$ Ala & M \\
VdRasGTPase & $\begin{array}{c}\text { Ras GTPase activator protein, } \\
\text { pathogenicity related }\end{array}$ & 3 & $3,707,621$ & $3,698,265$ & 2 & Leu $<->$ Phe/Gly & M \\
\hline
\end{tabular}

TABLE 4. Area under disease progress curve (AUDPC) values, yield ratios, regrowth disease severity indices (DSIs), and regrowth yield ratios of Black Mitcham peppermint and native spearmint after inoculations with representative Verticillium dahliae isolates from this study

\begin{tabular}{|c|c|c|c|c|c|}
\hline Mint species & Isolate & AUDPC ${ }^{w}$ & Yield ratio ${ }^{\mathrm{w}, \mathrm{x}}$ & Regrowth DSI ${ }^{y}$ & Regrowth yield ratio ${ }^{\mathrm{w}, \mathrm{x}}$ \\
\hline \multirow[t]{5}{*}{ Black Mitcham } & Control & $0.0 \mathrm{c}$ & $1.00 \mathrm{a}$ & $0.0 \mathrm{~b}$ & $1.00 \mathrm{a}$ \\
\hline & Vd-1127 & $49.7 \mathrm{a}$ & $0.65 \mathrm{~b}$ & $4.6 \mathrm{a}$ & $0.30 \mathrm{~b}$ \\
\hline & $15-059$ & $44.3 \mathrm{ab}$ & $0.73 \mathrm{ab}$ & $4.8 \mathrm{a}$ & $0.32 \mathrm{~b}$ \\
\hline & $97-098$ & $35.6 \mathrm{~b}$ & $0.87 \mathrm{ab}$ & $4.8 \mathrm{a}$ & $0.28 \mathrm{~b}$ \\
\hline & M-53 & $35.5 \mathrm{~b}$ & $0.84 \mathrm{ab}$ & $4.4 \mathrm{a}$ & $0.31 \mathrm{~b}$ \\
\hline \multirow[t]{4}{*}{ Native spearmint } & Control & $0.0 \mathrm{c}$ & $1.00 \mathrm{a}$ & $0.0 \mathrm{~b}$ & $1.00 \mathrm{a}$ \\
\hline & Vd-1127 & $5.0 \mathrm{c}$ & $0.96 \mathrm{a}$ & $0.0 \mathrm{~b}$ & $1.06 \mathrm{a}$ \\
\hline & $97-098$ & $6.0 \mathrm{c}$ & $0.91 \mathrm{ab}$ & $0.0 \mathrm{~b}$ & $0.94 \mathrm{a}$ \\
\hline & M-53 & $1.8 \mathrm{c}$ & $0.90 \mathrm{ab}$ & $0.0 \mathrm{~b}$ & $0.95 \mathrm{a}$ \\
\hline $\operatorname{Mint}^{\mathrm{z}}$ & & $<0.0001$ & 0.0002 & $<0.0001$ & $<0.0001$ \\
\hline Isolate & & $<0.0001$ & 0.0221 & 0.0062 & $<0.0001$ \\
\hline Mint $\times$ isolate & & $<0.0001$ & 0.0681 & $<0.0001$ & $<0.0001$ \\
\hline
\end{tabular}

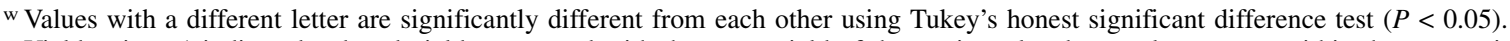

${ }^{x}$ Yield ratios $<1$ indicated reduced yields compared with the mean yield of the noninoculated control treatment within the same mint species.

y Values with a different letter are significantly different from each other within mint species using the Kruskal-Wallis test $(P<0.05)$.

${ }^{\mathrm{z}} P$ values are presented for the mint, isolate, and mint $\times$ isolate rows. 
that the potential exists for the evolution of more aggressive $V$. dahliae genotypes, even in the absence of sexual recombination (Wheeler and Johnson 2019). Although several VCGs were observed, VCG2B was the most common and the others were relatively rare. This observation matched the genetic data that resulted in the identification of one common genetic group and four relatively rare groups. These results are similar to those of Dung et al. (2013) who observed a predominant multilocus microsatellite haplotype among nine detected in a collection of 87 VCG2B isolates from mint. One perspective of this population structure may be that management and resistance-breeding efforts should be focused on this most common genetic group; however, management and breeding efforts targeting one group may lead to increased hostselection pressure and a "selective sweep," resulting in an increase in abundance of what are currently relatively uncommon groups (Atallah et al. 2011). Continuous monitoring of the genetic diversity in $V$. dahliae populations affecting mint production in the United States should be considered an important component when developing sustainable, integrated disease management strategies against Verticillium wilt.

\section{ACKNOWLEDGMENTS}

We thank Paul Camuso and Darrin Walenta for collecting additional $V$. dahliae isolates from mint in Oregon. The authors also thank Dennis Johnson and Krishna Subbarao for providing the V. dahliae isolates used for controls in mating type and pathogenic race assays. The technical support provided by Jeness Scott and Cara Boucher was greatly appreciated. Boucher's internship was made possible by the Oregon State University Branch Experiment Station Experiential Learning Internship program. The reference genome assembly used for this work, VdLs 17F (NCBI accession ID GCA_000952015.1), was kindly provided by Luigi Faino.

\section{LITERATURE CITED}

Alexander, L. J. 1962. Susceptibility of certain Verticillium-resistant tomato varieties to an Ohio isolate of pathogen. Phytopathology 52:998-1000.

Atallah, Z. K., Hayes, R. J., and Subbarao, K. V. 2011. Fifteen years of Verticillium wilt of lettuce in America's salad bowl: A tale of immigration, subjugation, and abatement. Plant Dis. 95:784-792.

Atallah, Z. K., Maruthachalam, K., du Toit, L., Koike, S. T., Davis, R. M., Klosterman, S. J., Hayes, R. J., and Subbarao, K. V. 2010. Population analyses of the vascular plant pathogen Verticillium dahliae detect recombination and transcontinental gene flow. Fungal Genet. Biol. 47: 416-422.

Atallah, Z. K., Maruthachalam, K., Vallad, G. E., Davis, R. M., Klosterman, S. J., and Subbarao, K. V. 2011 b. Analysis of Verticillium dahliae suggests a lack of correlation between genotypic diversity and virulence phenotypes. Plant Dis. 95:1224-1232.

Baergen, K. D., Hewitt, J. D., and St. Clair, D. A. 1993. Resistance of tomato genotypes to four isolates of Verticillium dahliae race 2. HortScience 28: 833-836.

Bhat, R. G., and Subbarao, K. V. 1999. Host range specificity in Verticillium dahliae. Phytopathology 89:1218-1225.

Botero, A. B., and Vazquez, A. N. 1982. A new race of Verticillium dahliae Kleb. Pages 177-178 in: Proceedings of the 10th International Sunflower Conference. International Sunflower Association, Surfers Paradise, Australia

Bradbury, P. J., Zhang, Z., Kroon, D. E., Casstevens, T. M., Ramdoss, Y., and Buckler, E. S. 2007. TASSEL: Software for association mapping of complex traits in diverse samples. Bioinformatics 23:2633-2635.

Browning, S. R., and Browning, B. L. 2007. Rapid and accurate haplotype phasing and missing-data inference for whole-genome association studies by use of localized haplotype clustering. Am. J. Hum. Genet. 81:1084-1097.

Butterfield, E. J., and DeVay, J. E. 1977. Reassessment of soil assays for Vertcillium dahliae. Phytopathology 67:1073-1078.

Cirulli, M., Bubici, G., Amenduni, M., Armengol, J., Berbegal, M., Jiménez-Gasco, M. del M., and Jiménez-Díaz, R. M. 2010. Verticillium wilt: A threat to artichoke production. Plant Dis. 94:1176-1187.

Cock, P. J. A., Fields, C. J., Goto, N., Heuer, M. L., and Rice, P. M. 2010. The Sanger FASTQ file format for sequences with quality scores, and the Solexa/Illumina FASTQ variants. Nucleic Acids Res. 38:1767-1771.

Daayf, F., Nicole, M., and Geiger, J.-P. 1995. Differentiation of Verticillium dahliae populations on the basis of vegetative compatibility and pathogenicity on cotton. Eur. J. Plant Pathol. 101:69-79.
Danecek, P., Auton, A., Abecasis, G., Albers, C. A., Banks, E., DePristo, M. A., Handsaker, R. E., Lunter, G., Marth, G. T., Sherry, S. T., McVean, G., Durbin, R., and the 1000 Genomes Project Analysis Group. 2011. The variant call format and VCFtools. Bioinformatics 27:2156-2158.

de Jonge, R., van Esse, H. P., Maruthachalam, K., Bolton, M. D., Santhanam, P., Saber, M. K., Zhang, Z., Usami, T., Lievens, B., Subbarao, K. V., and Thomma, B. P. H. J. 2012. Tomato immune receptor Ve1 recognizes effector of multiple fungal pathogens uncovered by genome and RNA sequencing. Proc. Natl. Acad. Sci. USA 109:5110-5115.

Dobinson, K. F., Harrington, M. A., Omer, M., and Rowe, R. C. 2000. Molecular characterization of vegetative compatibility group 4A and 4B isolates of Verticillium dahliae associated with potato early dying. Plant Dis. 84:1241-1245.

Douhan, L. I., and Johnson, D. A. 2001. Vegetative compatibility and pathogenicity of Verticillium dahliae from spearmint and peppermint. Plant Dis. 85:297-302.

Dung, J. K., Schroeder, B. K., and Johnson, D. A. 2010. Evaluation of Verticillium wilt resistance in Mentha arvensis and M. longifolia genotypes. Plant Dis. 94:1255-1260.

Dung, J. K. S., Peever, T. L., and Johnson, D. A. 2013. Verticillium dahliae populations from mint and potato are genetically divergent with predominant haplotypes. Phytopathology 103:445-459.

Elshire, R. J., Glaubitz, J. C., Sun, Q., Poland, J. A., Kawamoto, K., Buckler, E. S., et al. 2011. A robust, simple genotyping-by-sequencing (GBS) approach for high diversity species. PLoS One 6:e19379.

Faino, L., Seidl, M. F., Datema, E., van den Berg, G. C. M., Janssen, A., Wittenberg, A. H. J., and Thomma, B. P. H. J. 2015. Single-molecule realtime sequencing combined with optical mapping yields completely finished fungal genome. MBio 6:e00936-15.

Fick, G. N., and Zimmer, D. E. 1974. Monogenic resistance to Verticillium wilt in sunflowers. Crop Sci. 14:895-896.

Fradin, E. F., and Thomma, B. P. H. J. 2006. Physiology and molecular aspects of Verticillium wilt diseases caused by $V$. dahliae and V. albo-atrum. Mol. Plant Pathol. 7:71-86.

Fradin, E. F., Zhang, Z., Juarez Ayala, J. C., Castroverde, C. D. M., Nazar, R. N., Robb, J., Liu, C-. M., and Thomma, B. P. H. J. 2009. Genetic dissection of Verticillium wilt resistance mediated by tomato Ve1. Plant Physiol. 150:320-332.

Gurung, S., Short, D. P. G., Atallah, Z. K., and Subbarao, K. V. 2014. Clonal expansion of Verticillium dahliae in lettuce. Phytopathology 104:641-649.

Hastie, A. C. 1964. The parasexual cycle in Verticillium albo-atrum. Genet. Res. 5:305-315.

Hastie, A. C. 1973. Hybridization of Verticillium albo-atrum and Verticillium dahliae. Trans. Br. Mycol. Soc. 60:511-523.

Hayes, R. J., McHale, L. K., Vallad, G. E., Truco, M. J., Michelmore, R. W., Klosterman, S. J., Maruthachalam, K., and Subbarao, K. V. 2011. The inheritance of resistance to Verticillium wilt caused by race 1 isolates of Verticillium dahliae in the lettuce cultivar La Brillante. Zauchter Z. Theoretische Angew. Genetik. 123:509-517.

Hayes, R. J., Vallad, G. E., Qin, Q.-M., Grube, R. C., and Subbarao, K. V. 2007. Variation for resistance to Verticillium wilt in lettuce (Lactuca sativa L.). Plant Dis. 91:439-445.

Inderbitzin, P., Davis, R. M., Bostock, R. M., and Subbarao, K. V. 2011. The ascomycete Verticillium longisporum is a hybrid and a plant pathogen with an expanded host range. PLoS One 6:e18260.

Jiménez-Díaz, R. M., Mercado-Blanco, J., Olivares-García, C., Collado-Romero, M., Bejarano-Alcázar, J., Rodríguez-Jurado, D., Giménez-Jaime, A., GarcíaJiménez, J. and Armengol, J. 2006. Genetic and virulence diversity in Verticillium dahliae populations infecting artichoke in Eastern-Central Spain. Phytopathology 96:288-298.

Jiménez-Díaz, R. M., Olivares-García, C., Landa, B. B., Jiménez-Gasco, M. del Mar, and Navas-Cortés, J. A. 2011. Region-wide analysis of genetic diversity in Verticillium dahliae populations infecting olive in southern Spain and agricultural factors influencing the distribution and prevalence of vegetative compatibility groups and pathotypes. Phytopathology 101: 304-315.

Jiménez-Gasco, M. del M., Malcolm, G. M., Berbegal, M., Armengol, J., and Jiménez-Díaz, R. M. 2014. Complex molecular relationship between vegetative compatibility groups (VCGs) in Verticillium dahliae: VCGs do not always align with clonal lineages. Phytopathology 104:650-659.

Joaquim, T. R., and Crowe, R. C. 1990. Reassessment of vegetative compatibility relationships among strains of Verticillium dahliae using nitratenonutilizing mutants. Phytopathology 80:1160-1166.

Johnson, D. A., and Dung, J. K. S. 2010. Verticillium wilt of potato-The pathogen, disease and management. Can. J. Plant Pathol. 32:58-67.

Johnson, D. A., Zhang, H., and Alldredge, J. R. 2006. Spatial pattern of Verticillium wilt in commercial mint fields. Plant Dis. 90:789-797.

Jombart, T. 2008. adegenet: A R package for the multivariate analysis of genetic markers. Bioinformatics 24:1403-1405. 
Jombart, T., Devillard, S., and Balloux, F. 2010. Discriminant analysis of principal components: A new method for the analysis of genetically structured populations. BMC Genet. 11:94

Kabir, Z., Bhat, R. G., and Subbarao, K. V. 2004. Comparison of media for recovery of Verticillium dahliae from soil. Plant Dis. 88:49-55.

Klimes, A., Dobinson, K. F., Thomma, B. P. H. J., and Klosterman, S. J. 2015. Genomics spurs rapid advances in our understanding of the biology of vascular wilt pathogens in the genus Verticillium. Annu. Rev. Phytopathol. 53:181-198.

Knaus, B. J., and Grünwald, N. J. 2017. vcfr: A package to manipulate and visualize variant call format data in R. Mol. Ecol. Resour. 17:44-53.

Knaus, B. J., and Grünwald, N. J. 2018. Inferring variation in copy number using high throughput sequencing data in R. Front. Genet. 9:123.

Li, H., and Durbin, R. 2009. Fast and accurate short read alignment with Burrows-Wheeler transform. Bioinformatics 25:1754-1760.

Martín-Sanz, A., Rueda, S., García-Carneros, A. B., González-Fernández, S., Miranda-Fuentes, P., Castuera-Santacruz, S., and Molinero-Ruiz, L. 2018. Genetics, host range, and molecular and pathogenic characterization of Verticillium dahliae from sunflower reveal two differentiated groups in Europe. Front. Plant Sci. 9:288.

McGuire, I. C., Davis, J. E., Double, M. L., MacDonald, W. L., Rauscher, J. T., McCawley, S., and Milgroom, M. G. 2005. Heterokaryon formation and parasexual recombination between vegetatively incompatible lineages in a population of the chestnut blight fungus, Cryphonectria parasitica. Mol. Ecol. 14:3657-3669.

Milgroom, M. G., Jimenez-Gasco, M. del M., Olivares-Garcia, C., Drott, M. T., and Jimenez-Diaz, R. M. 2014. Recombination between clonal lineages of the asexual fungus Verticillium dahliae detected by genotyping by sequencing. PLoS One 9:e106740.

Milgroom, M. G., Jiménez-Gasco, M. del M., Olivares-García, C., and Jiménez-Díaz, R. M. 2016. Clonal expansion and migration of a highly virulent, defoliating lineage of Verticillium dahliae. Phytopathology 106:1038-1046.

Pegg, G., and Brady, B., eds. 2002. Verticillium Wilts. CAB International, Oxford, UK.

R Core Team. 2017. R: A Language and Environment for Statistical Computing. R Foundation for Statistical Computing, Vienna, Austria. https:// www.R-project.org/

Rafiei, V., Banihashemi, Z., Bautista-Jalon, L. S., Jiménez-GascoM. del M., Turgeon, B. G., and Milgroom, M. G. 2018. Population genetics of Verticillium dahliae in Iran based on microsatellite and single nucleotide polymorphism markers. Phytopathology 108:780-788.
Schaible, L., Cannon, O. S., and Waddoups, V. 1951. Inheritance of resistance to Verticillium wilt in a tomato cross. Phytopathology 41: 986-990.

Short, D. P. G., Gurung, S., Hu, X., Inderbitzin, P., and Subbarao, K. V. 2014a. Maintenance of sex-related genes and the co-occurrence of both mating types in Verticillium dahliae. PLoS One 9:e112145.

Short, D. P. G., Gurung, S., Maruthachalam, K., Atallah, Z. K., and Subbarao, K. V. 2014b. Verticillium dahliae race 2-specific PCR reveals a high frequency of race 2 strains in commercial spinach seed lots and delineates race structure. Phytopathology 104:779-785.

Turgeon, B. G. 1998. Application of mating type gene technology to problems in fungal biology. Annu. Rev. Phytopathol. 36:115-137.

Turgeon, B. G., and Yoder, O. C. 2000. Proposed nomenclature for mating type genes of filamentous ascomycetes. Fungal Genet. Biol. 31:1-5.

Usami, T., Itoh, M., and Amemiya, Y. 2008. Mating type gene MAT1-2-1 is common among Japanese isolates of Verticillium dahliae. Physiol. Mol. Plant Pathol. 73:133-137.

Usami, T., Itoh, M., and Amemiya, Y. 2009. Asexual fungus Verticillium dahliae is potentially heterothallic. J. Gen. Plant Pathol. 75:422-427.

Usami, T., Momma, N., Kikuchi, S., Watanabe, H., Hayashi, A., Mizukawa, M., Yoshino, K., and Ohmori, Y. 2017. Race 2 of Verticillium dahliae infecting tomato in Japan can be split into two races with differential pathogenicity on resistant rootstocks. Plant Pathol. 66:230-238.

Vallad, G. E., Qin, Q.-M., Grube, R., Hayes, R. J., and Subbarao, K. V. 2006. Characterization of race-specific interactions among isolates of Verticillium dahliae pathogenic on lettuce. Phytopathology 96:1380-1387.

Weiland, J. E., Benedict, C., Zasada, I. A., Scagel, C. R., Beck, B. R., Davis, A., Graham, K., Peetz, A., Martin, R. R., Dung, J. K. S., Gaige, A. R., and Thiessen, L. 2018. Late-summer disease symptoms in Western Washington red raspberry fields associated with co-occurrence of Phytophthora rubi, Verticillium dahliae, and Pratylenchus penetrans, but not Raspberry bushy dwarf virus. Plant Dis. 102:938-947.

Wheeler, D. L., and Johnson, D. A. 2019. Does co-inoculation with different Verticillium dahliae genotypes affect the host or fungus? Phytopathology 109:780-786.

Wickham, H. 2016. ggplot2: Elegant Graphics for Data Analysis. 2nd ed. Springer International Publishing, Dordrecht, Netherlands.

Wobbrock, J. O., Findlater, L., Gergle, D., and Higgins, J. J. 2011. The aligned rank transform for nonparametric factorial analyses using only anova procedures. Page 143 in: Proceedings of the 2011 Annual Conference on Human Factors in Computing Systems. ACM Press, Vancouver, British Columbia, Canada. 